\title{
SCGB2A1 is a novel prognostic marker for colorectal cancer associated with chemoresistance and radioresistance
}

\author{
KOJI MUNAKATA $^{1 *}$, MAMORU UEMURA ${ }^{1 *}$, ICHIRO TAKEMASA $^{1}$, MIYUKI OZAKI $^{2}$, MASAMITSU KONNO $^{2}$, \\ JUNICHI NISHIMURA $^{1}$, TAISHI HATA ${ }^{1}$, TSUNEKAZU MIZUSHIMA $^{1}$, NAOTSUGU HARAGUCHI ${ }^{1}$, \\ SHINGO NOURA ${ }^{3}$, MASAKAZU IKENAGA $^{4}$, SHU OKAMURA $^{5}$, MUTSUMI FUKUNAGA $^{6}$, \\ KOHEI MURATA $^{5}$, HIROFUMI YAMAMOTO ${ }^{1}$, YUICHIRO DOKI $^{1}$ and MASAKI MORI ${ }^{1}$ \\ Departments of ${ }^{1}$ Gastroenterological Surgery and ${ }^{2}$ Frontier Science for Cancer and Chemotherapy, \\ Graduate School of Medicine, Osaka University; ${ }^{3}$ Department of Surgery, Osaka Medical Center for Cancer \\ and Cardiovascular Diseases; ${ }^{4}$ Department of Surgery, Osaka Rosai Hospital; ${ }^{5}$ Department of Surgery, \\ Suita Municipal Hospital; ${ }^{6}$ Department of Surgery, Sakai City Hospital, Japan
}

Received November 30, 2013; Accepted December 27, 2013

DOI: $10.3892 /$ ijo.2014.2316

\begin{abstract}
We recently showed that liver metastatic tissue from patients with colorectal cancer (CRC) was a useful model for identifying novel, hypoxia-inducible genes and prognostic markers. We showed that the expression of secretoglobin, family $2 \mathrm{~A}$, member 1 (SCGB2A1) was a potential prognostic factor for CRC. Here, we further evaluated the prognostic impact and function of SCGB2A1 in 222 patients with CRC. The impact of SCGB2A1 expression on disease-free survival (DFS) and overall survival (OS) was assessed with mRNA expression profiling. The function of SCGB2A1 was analyzed by evaluating mRNA expression profiles in cells derived from patients with $\mathrm{CRC}$ and by testing the effects of transfecting SCGB2A1 into different CRC-derived cell lines. We evaluated the effects of SCGB2A1 on proliferation, chemosensitivity, radiation sensitivity and sphere formation. Univariate and multivariate analyses indicated that the expression of SCGB2A1 was an independent prognostic factor for CRC $(\mathrm{p}<0.05)$, together with lymph node metastasis $(\mathrm{p}<0.05)$. Enforced expression of SCGB2A1 in CRC-derived cell lines promoted proliferation (DLD1, SW480 and LoVo cells; $\mathrm{p}<0.05$ ), decreased chemosensitivity to 5-fluorouracil and oxaliplatin (DLD1 and SW480 cell lines; $\mathrm{p}<0.05$ ), and significantly increased the viability of irradiated cells (DLD1, SW480 and LoVo cell lines; p<0.05). SCGB2A1 expression
\end{abstract}

Correspondence to: Dr Mamoru Uemura, Department of Gastroenterological Surgery, Graduate School of Medicine, Osaka University, 2-2 Yamadaoka, E-2, Suita, Osaka 565-0871, Japan

E-mail: muemura@gesurg.med.osaka-u.ac.jp

${ }^{*}$ Contributed equally

Key words: SCGB2A1, mammaglobin-B, chemoresistance, radioresistance, treatment resistance, colorectal cancer was also correlated to cancer stemness-related genes (Wnt, Zeb1 and Twist). Consistent with this correlation, SCGB2A1 expressing cells (SW480) showed increased sphere formation $(\mathrm{p}<0.05)$. These results indicated that SCGB2A1 represented a novel, prognostic factor for CRC, and that expression of SCGB2A1 correlated with chemoresistance, radioresistance and cancer cell stemness.

\section{Introduction}

Colorectal cancer (CRC) is one of the most common human malignancies worldwide. Despite recent advances in treatment with chemotherapy and radiation therapy, CRC remains a major cause of cancer death (1). Thus, there is a crucial need to explore novel cancer-related genes that may serve as diagnostic markers and molecular targets in CRC therapy.

A hypoxic microenvironment is associated with many solid tumors, including breast cancer $(2)$, prostate cancer $(3,4)$, brain tumor (5), malignant melanomas $(6,7)$, lung cancer (8), liver cancer $(9,10)$, ovarian cancer $(11,12)$, and CRC $(13)$. Furthermore, intratumoral hypoxia affects every major aspect of cancer biology, including cell invasion, metastasis, and determination of cell death (14).

Many molecules in the hypoxia-response pathway are good candidates for therapeutic targeting (15-17). The anti-VEGF antibody, bevacizumab, is used clinically for treating several human cancers (18); this supports the notion that hypoxiainduced genes are clinically-relevant therapeutic targets. Therefore, the identification of novel hypoxia-inducible genes holds great potential for the development of additional cancer therapies.

We previously reported that liver metastatic tissue derived from patients with CRC was a useful in vivo model for identifying novel hypoxia-inducible genes and prognostic markers. These markers included the mRNA expression levels of Jumonji domain containing 1A (JMJD1A), adrenomedullin (ADM), Ephrin-A1 (EFNA1), and procollagen-lysine, 2-oxoglutarate 5-dioxygenase 2 (PLOD2) (19-22). In those experiments, 
we also found that the mRNA expression of secretoglobin, family $2 \mathrm{~A}$, member 1 (SCGB2A1) was highly induced in hypoxic regions of metastasized liver (fold-change, 1.57). Thus, we hypothesized that SCGB2A1 expression may be a novel prognostic factor in patients with CRC.

The aim of the present study was to examine the prognostic impact of SCGB2A1 and the biological significance of SCGB2A1 in CRC. We reported previously (23-25) that SCGB2A1 was a useful marker in several cancers for the molecular detection of minimal residual disease in lymph nodes, but the mechanism remains unknown (26-29).

Here, we found that SCGB2A1 was an independent prognostic factor, and expression of SCGB2A1 promoted both chemoresistance and radioresistance.

Cancer cell stemness is a primary underlying mechanism that contributes to resistance to chemotherapy and radiation therapy $(30,31)$. Our data indicated that cancer stemness was enhanced by forced expression of SCGB2A1. Thus, our findings may provide clues for the development of a novel anticancer therapy.

\section{Materials and methods}

Cell lines and culture conditions. Human CRC-derived cell lines, DLD1, SW480, and LoVo, were obtained from the American Type Culture Collection. Cells were grown in Dulbecco's modified Eagle's medium (DMEM) supplemented with $10 \%$ fetal bovine serum, $100 \mathrm{U} / \mathrm{ml}$ penicillin and $100 \mu \mathrm{g} /$ $\mathrm{ml}$ streptomycin at $37^{\circ} \mathrm{C}$ in a humidified incubator with $5 \% \mathrm{CO}_{2}$.

Clinical samples and microarray analysis. For microarray analysis, we prospectively collected 1,978 primary CRC samples from consecutive patients who had curative operations in 2003 to 2006 from Osaka University Hospital and its nine associated hospitals (32). Tumor samples were consecutively collected from a total of 222 CRC patients for microarray analysis. Microarray analysis was carried out as described previously (33) using an oligonucleotide microarray covering 30,000 human probes (AceGene; DNA Chip Research, Inc. and Hitachi Software Engineering Co. Ltd.). The mean followup times were $42.9 \pm 28.9$ months for patients with disease-free survival (DFS) and 56.7 \pm 20.4 months for all surviving patients [overall survival (OS)]. Table I shows the clinicopathological features of patients from each institute, including gender, tumor location, extent of wall invasion, lymph node metastasis, histologic grade, Dukes' stage, and vessel invasion. In this study, no patient received preoperative chemotherapy or irradiation. After surgery, patients with Dukes' stage C/D tumors were generally treated with 5-fluorouracil (5-FU)-based chemotherapy.

Transfection of vector. DLD1, SW480 and LoVo were transfected with an SCGB2A1 expression vector with the FuGENE ${ }^{\circledR} 6$ transfection reagent (Promega, USA), according to the manufacturer's protocol. Control cells were transfected with the same method, but with an empty control vector.

Proliferation assay. Overexpressing SCGB2A1 cell lines and control cell lines were seeded in 96-well plates $(2,000$ cells/ well) and grown at $37^{\circ} \mathrm{C}$ with $5 \% \mathrm{CO}_{2}$. After 24 and $72 \mathrm{~h}$, we assayed cell viability with a Cell Counting Kit-8 (Dojindo, Japan), according to themanufacturer's instructions. After 2-h pre-incubations in the assay solution, the viable cell number in each well was determined from the absorbance at $450 \mathrm{~nm}$ (OD 450), measured with a microplate reader (Bio-Rad Model 680 XR, USA).

Chemosensitivity assay. We tested cell sensitivity to 5-FU and oxaliplatin (L-OHP), which are generally used in chemotherapy for CRC. We seeded 2,000 cells/well in 96-well plates and incubated at $37^{\circ} \mathrm{C}$ with $5 \% \mathrm{CO}_{2}$. After $24 \mathrm{~h}$, the culture medium was replaced with fresh medium in the presence of 5-FU or L-OHP at predetermined $\mathrm{IC}_{50}$ concentrations. After 24 and $48 \mathrm{~h}$ of treatment with chemotherapy, we assayed cell viability with same method used in the proliferation assay.

Radiation sensitivity assay. To measure radiation sensitivity, each cell line was seeded at 2,000 cells/well into 96-well plates and incubated at $37^{\circ} \mathrm{C}$ with $5 \% \mathrm{CO}_{2}$. After $24 \mathrm{~h}, \mathrm{a}{ }^{137} \mathrm{Cs}$ Gamma Cell 40 Exactor (MDS Nordion, Canada) was used to irradiate DLD1 and SW480 cells at 8 Gy and LoVo cells at $6 \mathrm{~Gy}$. After 24 and $72 \mathrm{~h}$ of treatment with radiation therapy, we assayed cell viability with same method used in the proliferation assay.

Sphere formation assay. The sphere formation assay was performed essentially as described previously (34). In brief, single cells were plated in 96-well ultralow attachment plates (Corning Inc., USA) at a density of 100 cells/well and grown in tumorspheric culture medium (Dulbecco's modified Eagle's medium, DMEM/F-12), supplemented with $20 \mathrm{ng} / \mathrm{ml}$ human platelet growth factor (Sigma-Aldrich, USA), $20 \mathrm{ng} / \mathrm{ml}$ epidermal growth factor (Invitrogen, USA) and $1 \%$ antibioticantimycotic solution (Invitrogen) at $37^{\circ} \mathrm{C}$ in a humidified atmosphere of $95 \%$ air and $5 \% \mathrm{CO}_{2}$. We counted the number of spheres $\geq 100 \mu \mathrm{m}$ in all wells and evaluated differences in the average number/well.

Statistical analysis. Statistical analysis was performed with the StatView 5.0 program (Abacus Concepts, Inc., USA). The Kaplan-Meier method was used to examine DFS and OS, and the log-rank test was used to determine statistical significance. A Cox proportional hazard model was used to assess the risk ratio with simultaneous contributions from several covariates. Statistical analysis was performed with the Student's t-test or Fisher's exact test for categorical data and with the Mann-Whitney U test for non-parametric data. Correlation significance was assessed with Pearson's correlation coefficient-test. Values of $p<0.05$ denoted a statistically significant difference.

\section{Results}

Relationship between SCGB2A1 expression and clinicopathological factors. Patients were divided into two groups (high or low) according to whether the SCGB1A1 mRNA expression level was above or below the median SCGB2A1 expression value. The relationships between SCGB2A1 mRNA expression and clinicopathological factors were examined (Table I). 
Table I. Relationship between SCGB2A1 expression and clinicopathological factors in patients with colorectal cancer.

\begin{tabular}{|c|c|c|c|c|}
\hline & \multirow[b]{2}{*}{ Total $n=222$} & \multicolumn{2}{|c|}{ SCGB2A1 mRNA expression } & \multirow[b]{2}{*}{ P-value } \\
\hline & & Low $(n=111)$ & $\operatorname{High}(\mathrm{n}=111)$ & \\
\hline Age (years) & $66.2 \pm 10.0$ & $65.8 \pm 9.7$ & $66.7 \pm 10.3$ & 0.61 \\
\hline \multicolumn{5}{|l|}{ Gender } \\
\hline Male/female & $133 / 89$ & $62 / 49$ & $71 / 40$ & 0.27 \\
\hline \multicolumn{5}{|l|}{ Tumor location } \\
\hline Colon/rectum & $141 / 81$ & $77 / 34$ & $64 / 47$ & 0.09 \\
\hline \multicolumn{5}{|l|}{ Depth of invasion ${ }^{\mathrm{a}}$} \\
\hline $\mathrm{mp} / \mathrm{ss}$ & $26 / 196$ & $8 / 103$ & $18 / 93$ & 0.06 \\
\hline \multicolumn{5}{|l|}{ Lymph node metastasis } \\
\hline Present/absent & $109 / 113$ & $52 / 59$ & $57 / 54$ & 0.59 \\
\hline \multicolumn{5}{|l|}{ Histological grade } \\
\hline Well differentiated/others & $53 / 169$ & $28 / 83$ & $25 / 86$ & 0.75 \\
\hline \multicolumn{5}{|l|}{ Dukes' stage } \\
\hline $\mathrm{AB} / \mathrm{CD}$ & $108 / 114$ & $58 / 53$ & $50 / 61$ & 0.35 \\
\hline \multicolumn{5}{|l|}{ Vessel invasion } \\
\hline Present/absent & $184 / 38$ & $89 / 22$ & $95 / 16$ & 0.37 \\
\hline
\end{tabular}

${ }^{\mathrm{a}} \mathrm{mp}$, muscularis propria layer or above; ss, subserosa level or below.

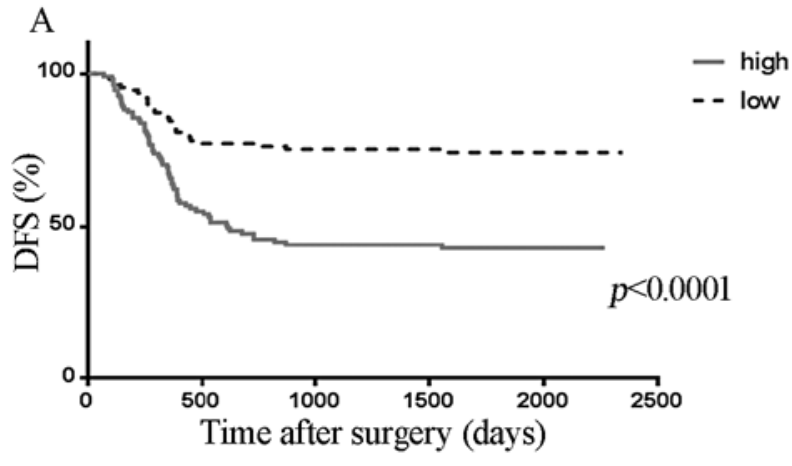

$\mathrm{B}$

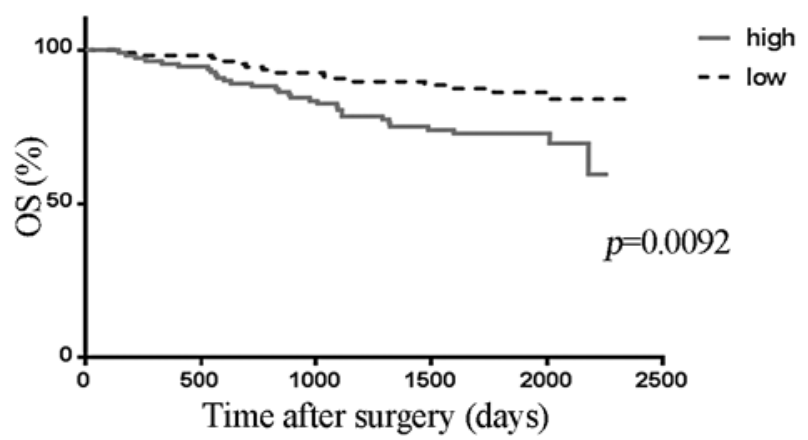

Figure 1. Survival curve analysis of patients with colorectal cancer and different levels of SCGB2A1 expression. (A) Kaplan-Meier survival curves of patients with colorectal cancer that exhibited low (continuous line) or high (broken line) SCGB2A1 mRNA expression. Patients in the high SCGB2A1 mRNA expression group had a lower disease-free survival (DFS) rate than those in the low expression group $(\mathrm{p}<0.0001)$. (B) Patients in the high SCGB2A1 mRNA expression group had a lower overall survival rate (OS) than those in the low expression group $(\mathrm{p}=0.0092)$.
There were no significant differences between groups in age, gender, tumor location, depth of tumor invasion, lymph node metastasis, histological grade, Dukes' stage or vessel invasion.

Impact of SCGB2A1 mRNA expression on disease-free survival. The DFS curves were stratified according to SCGB2A1 expression levels. The DFS was significantly longer in the low SCGB2A1 expression group compared to that in the high SCGB2A1 expression group ( $\mathrm{p}<0.0001$; Fig. 1A).

In a univariate analysis, the level of SCGB2A1 mRNA expression and various other clinicopathological parameters were evaluated for their impact on DFS (Table II). The DFS was significantly associated with the depth of invasion $(p=0.0082)$, lymph node metastasis $(p<0.0001)$, histological grade $(p=0.0193)$, vessel invasion $(p=0.0001)$ and the expression of SCGB2A1 $(\mathrm{p}<0.0001)$.

A multivariate Cox regression analysis demonstrated that the mRNA expression of SCGB2A1 was a significant prognostic factor for DFS ( $\mathrm{p}<0.0001$; Table II). Among the other covariates, the depth of invasion, lymph node metastasis and vessel invasion were significant prognostic factors $(\mathrm{p}=0.0321$, 0.0386 and 0.0298 , respectively; Table II).

Impact of SCGB2A1 expression on overall survival. The OS curves were stratified according to SCGB2A1 expression levels. The OS was significantly longer in the low SCGB2A1 expression group compared to that in the high SCGB2A1 expression group ( $\mathrm{p}=0.0092$; Fig. 1B).

In a univariate analysis, mRNA expression of SCGB2A1 and various clinicopathological parameters were evaluated for 
Table II. Analysis of associations between disease-free survival and clinicopathological factors, including SCGB2A1 mRNA expression.

\begin{tabular}{|c|c|c|c|c|}
\hline \multirow[b]{2}{*}{ Variable } & \multirow{2}{*}{$\frac{\text { Univariate analysis }}{\text { P-value }}$} & \multicolumn{3}{|c|}{ Multivariate analysis } \\
\hline & & Relative risk & $95 \% \mathrm{CI}$ & P-value \\
\hline Tumor location (colon/rectum) & 0.0655 & & & \\
\hline Depth of invasion ${ }^{\mathrm{a}}(\mathrm{mp} / \mathrm{ss})$ & 0.0082 & 0.327 & $0.118-0.909$ & 0.0321 \\
\hline Lymph node metastasis $(+/-)$ & $<0.0001$ & 1.592 & $1.025-2.473$ & 0.0386 \\
\hline Histological grade (well differentiated/others) & 0.0193 & 1.276 & $0.711-2.293$ & 0.4141 \\
\hline Dukes' stage $(\mathrm{AB} / \mathrm{CD})$ & $<0.0001$ & & & \\
\hline Vessel invasion (yes/no) & 0.0001 & 3.207 & $1.121-9.177$ & 0.0298 \\
\hline SCGB2A1 (high/low) & $<0.0001$ & 2.784 & $1.775-4.369$ & $<0.0001$ \\
\hline
\end{tabular}

${ }^{\mathrm{a}} \mathrm{mp}$, muscularis propria layer or above; ss, subserosa level or below.

Table III. Analysis of associations between overall survival and clinicopathological factors, including SCGB2A1 mRNA expression.

\begin{tabular}{|c|c|c|c|c|}
\hline \multirow[b]{2}{*}{ Variable } & \multirow{2}{*}{$\frac{\text { Univariate analysis }}{\text { P-value }}$} & \multicolumn{3}{|c|}{ Multivariate analysis } \\
\hline & & Relative risk & $95 \% \mathrm{CI}$ & P-value \\
\hline Tumor location (colon/rectum) & 0.8824 & & & \\
\hline Depth of invasion ${ }^{\mathrm{a}}(\mathrm{mp} / \mathrm{ss})$ & 0.2763 & & & \\
\hline Lymph node metastasis (+/-) & $<0.0001$ & 4.065 & $1.911-8.643$ & 0.0003 \\
\hline Histological grade (well differentiated/others) & 0.0632 & & & \\
\hline Dukes' stage $(\mathrm{AB} / \mathrm{CD})$ & $<0.0001$ & & & \\
\hline Vessel invasion (yes/no) & 0.0201 & 2.192 & $0.506-9.493$ & 0.2939 \\
\hline SCGB2A1 (high/low) & 0.0092 & 1.988 & $1.067-3.704$ & 0.0305 \\
\hline
\end{tabular}

${ }^{\mathrm{a}} \mathrm{mp}$, muscularis propria layer or above; ss, subserosa level or below.

their impact on OS. The OS was significantly associated with lymph node metastasis $(p<0.0001)$, vessel invasion $(p=0.0201)$ and the expression of SCGB2A1 ( $\mathrm{p}=0.0092)$ (Table III).

A multivariate Cox regression analysis demonstrated that the mRNA expression of SCGB2A1 was a significant prognostic factor for OS ( $p=0.0305$; Table III). Among the other covariates, only lymph node metastasis was a significant prognostic factor $(\mathrm{p}=0.0003$; Table III).

Proliferation assay. To explore $S C G B 2 A 1$ gene function, we first transfected a plasmid that encoded SCGB2A1 or the empty control vector into CRC-derived cell lines, DLD1, SW480 and LoVo. Our results showed that upregulation of SCGB2A1 elicited significant cell proliferation compared to cells transfected with the empty control vector at $72 \mathrm{~h}(\mathrm{p}<0.05)$ (Fig. 2).

Chemoresistance and radioresistance conferred by SCGB2AI in CRC cells. CRC-derived cells (DLD1 and SW480) transfected with SCGB2A1 exhibited much greater resistance to the anticancer drugs, 5-FU and L-OHP, than cells transfected with empty control vector at $48 \mathrm{~h}(\mathrm{p}<0.05)$ (Fig. 3). Likewise, upregulation of SCGB2A1 in DLD1, SW480 and LoVo cells conferred stronger radioresistance compared to cells transfected with empty control vector at $72 \mathrm{~h}(\mathrm{p}<0.05)$ (Fig. 4).

Correlation of SCGB2A1 with cancer stemness-related genes and sphere formation. For elucidation of the chemoresistance and radioresistance mechanism, we analyzed the microarray data to identify genes that were correlated with $S C G B 2 A 1$ expression. We found that $S C G B 2 A 1$ was correlated with the expression of wingless and INT-1 (Wnt; Fig. 5A), zinc finger E-box binding homeobox 1 (Zebl; Fig. 5B) and Twist (Fig. 5C).

Recently, the development of cancer stem cells (CSCs) was proposed to be one of the major mechanisms underlying treatment resistance. One study demonstrated a relationship between colon CSCs and Wnt activity (35). Another study showed that Zebl induction was associated with the epithelialmesenchymal transition, and it was also related to CSCs (36). 

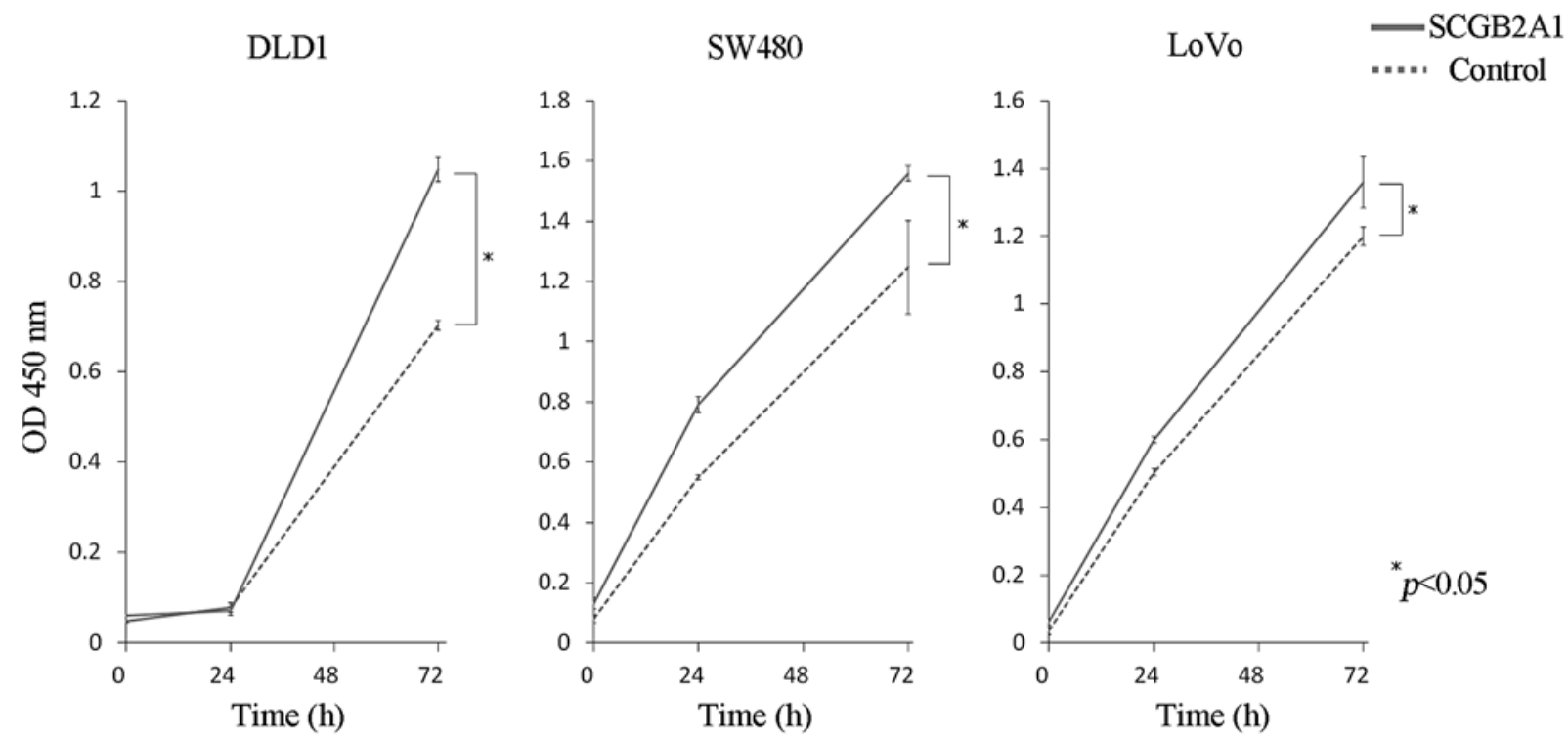

Figure 2. Proliferation shown as the number of viable colorectal cancer (CRC) cells transfected with SCGB2A1 or control vector. Upregulation of SCGB2A1 (continuous line) induced significantly more proliferation than baseline SCGB2A1 levels (broken line) in CRC cells after $72 \mathrm{~h}$ ("p<0.05). Cell numbers were determined from the absorbance at $450 \mathrm{~nm}$ (OD 450).

A

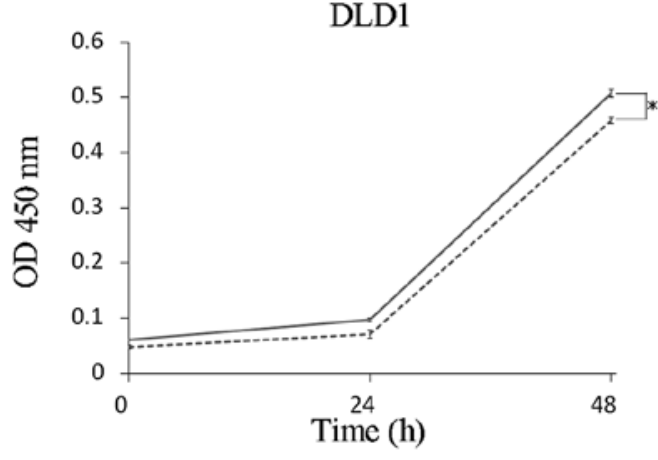

B

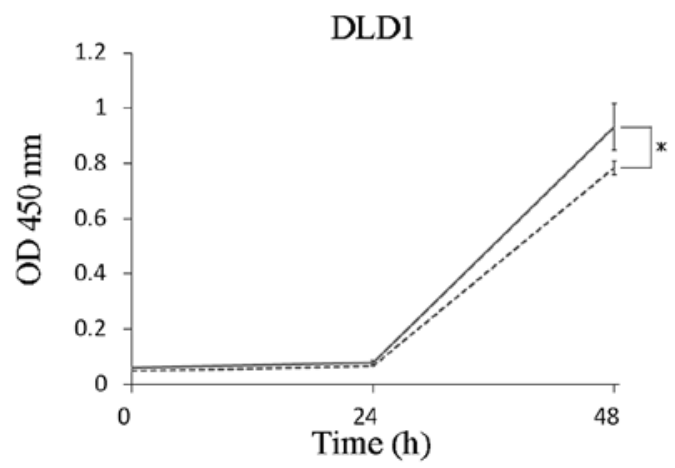

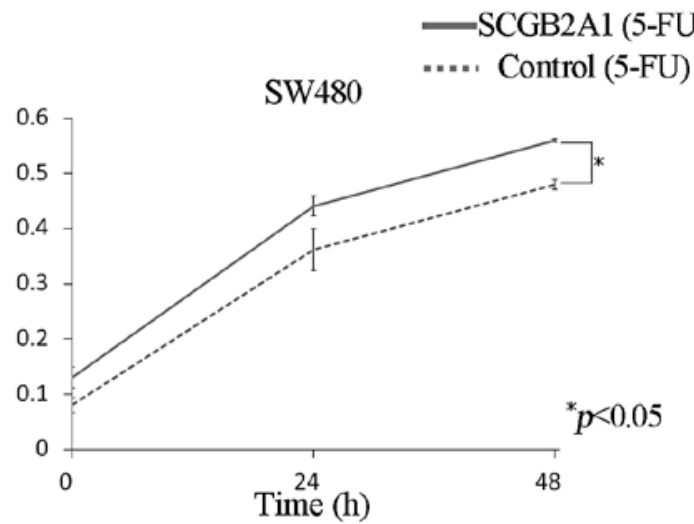

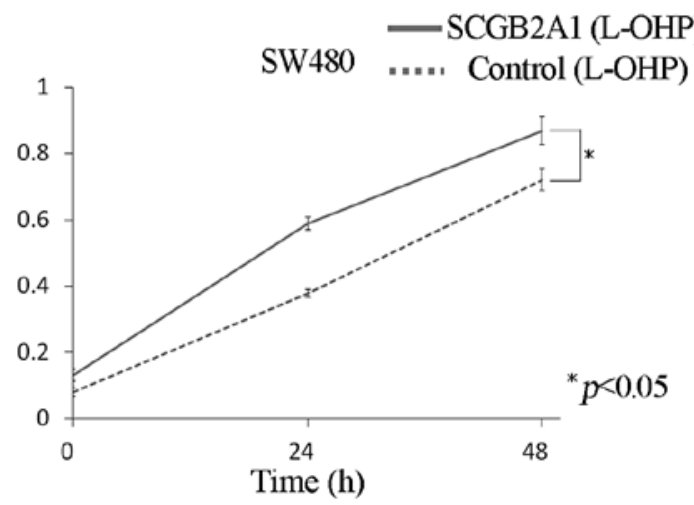

Figure 3. Chemoresistance shown as the number of viable colorectal cancer (CRC) cells transfected with SCGB2A1 or control vector. (A) 5-fluorouracil (5-FU) sensitivity assay. (B) Oxaliplatin (L-OHP) sensitivity assay. Upregulation of SCGB2A1 (continuous lines) in CRC cells (DLD1 and SW480) induced higher viability than cells transfected with empty control vector (broken lines) in the presence of anticancer drugs ( $\left.{ }^{*} \mathrm{p}<0.05\right)$. Cell numbers were determined from the absorbance at $450 \mathrm{~nm}(\mathrm{OD} 450)$.

We conducted a sphere formation assay to evaluate whether SCGB2A1 overexpressing cells acquired cancer cell stemness. The appearance of spheres, which form after several weeks, is considered indicative of the ability to self-renew. This phenomenon would be consistent with development of a CSC phenotype (34). After 3 weeks in culture, sphere formation was observed in the SW480 cell line, but not the other cell lines (Fig. 6A). Also, we found that upregulation of $S C G B 2 A I$ 

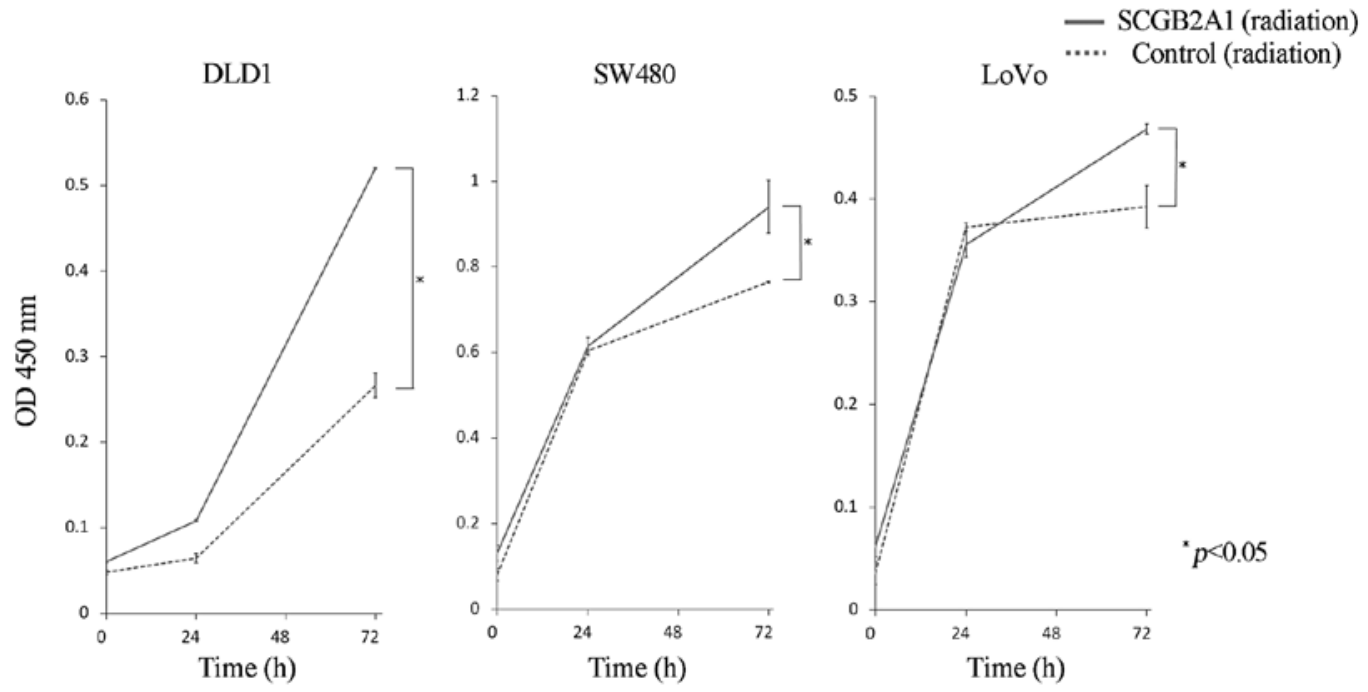

Figure 4. Radioresistance shown as the number of viable colorectal cancer (CRC) cells transfected with SCGB2A1 or control vector. Upregulation of SCGB2A1 (continuous lines) in CRC cells (DLD1, SW480, and LoVo) induced higher viability than cells transfected with empty control vector (broken lines) after radiation treatment $\left({ }^{*} \mathrm{p}<0.05\right)$. Cell numbers were determined from the absorbance at $450 \mathrm{~nm}$ (OD 450).

A

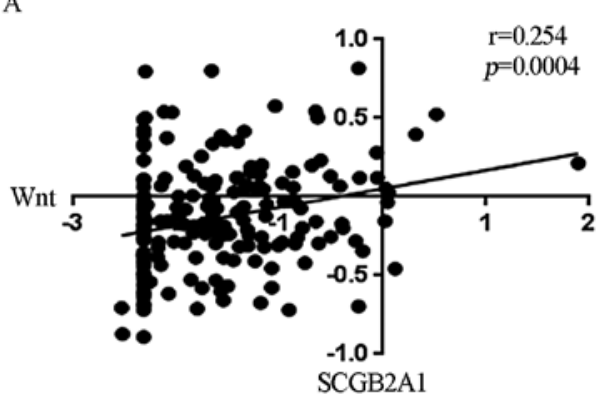

B

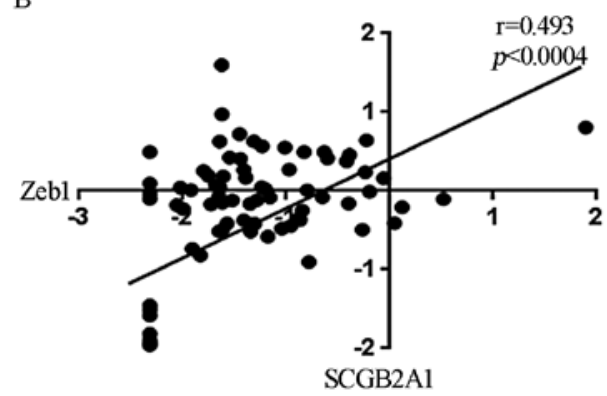

$\mathrm{C}$

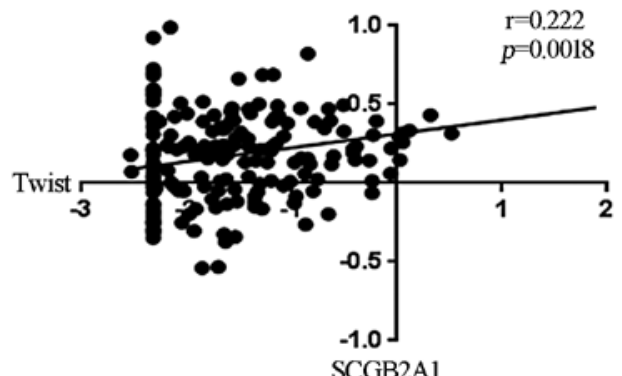

Figure 5. Correlation analysis of mRNA expression levels of SCGB2A1 and genes related to cancer stemness (Wnt, Zebl and Twist). Microarrays of specimens from patients with CRC were evaluated, and expression levels of SCGB2A1 were correlated to expression levels of cancer stemness-related genes; (A) Wnt ( $\mathrm{n}=193)$; (B) Zeb1 ( $\mathrm{n}=86)$; and (C) Twist $(\mathrm{n}=195)$. Significant correlations ( $\mathrm{p}=0.0045,0.0039$ and $<0.0001$, respectively) were indicated, based on Pearson's correlation coefficient-test (correlation coefficients: $\mathrm{r}=0.254,0.493$ and 0.222 , respectively).

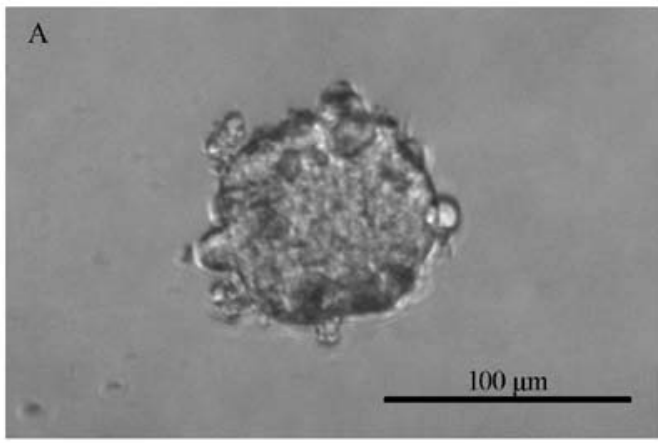

B

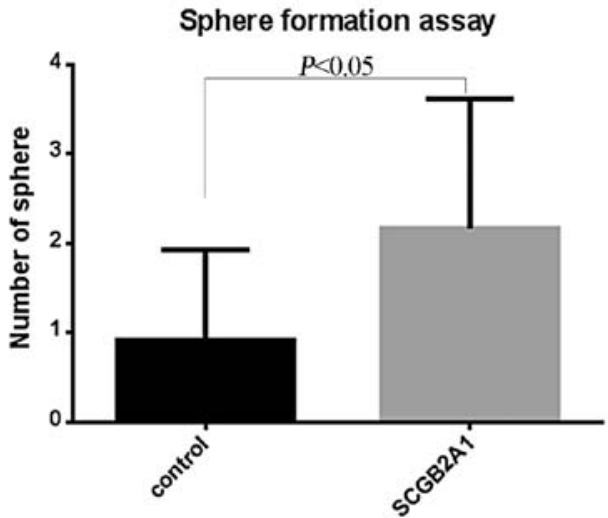

Figure 6. Sphere formation in colorectal cancer (CRC) cells transfected with SCGB2A1 or control vector. (A) We counted the number of spheres that formed on SW480 cells. Scale bar, $100 \mu \mathrm{m}$. (B) Based on the average number of spheres per well, the sphere forming ability was stronger in SCGB2A1overexpressing cells than in control cells transfected with the empty control vector $(\mathrm{p}<0.05)$. This suggested a relationship between SCGB2A1 expression and cancer-stemness.

could generate many more spheres compared to baseline $S C G B 2 A 1$ levels in cells transfected with the empty control vector $(\mathrm{p}<0.0001)$ (Fig. 6B). 


\section{Discussion}

The SCGB2A1 (mammaglobin B) gene encodes a small secreted protein of the uteroglobin superfamily. This superfamily includes nine human secretoglobins that are localized on chromosome 11q12.2 (37). SCGB2Al was first isolated by Becker et al in 1998 (38).

SCGB2A1 is considered a candidate marker for the molecular detection of several minimal cancers in lymph nodes (23-29) and for the diagnosis of occult tumor cells in effusions from patients with various malignancies, including gynecological cancers (39). However, the biological function of SCGB2A1 has not yet been clarified in CRC.

The present report was the first to show that SCGB2A1 could be an important prognostic factor for patients with CRC. We showed that enhanced expression of SCGB2A1 in CRC cells might confer the property of treatment resistance.

We previously established a method for finding clinically important, hypoxia-inducible genes from samples of liver that had metastasized from CRC (19-22). In a chronically hypoxic environment, cancer cells undergo genetic and adaptive changes that allow them to become more clinically aggressive, and they develop resistance to irradiation and chemotherapy $(15,16,40)$. An efficient therapeutic strategy for combating those cell types is essential for overcoming cancer. However, it is difficult to identify important hypoxia-inducible genes that are related to clinical cancer biology in vitro, because cancer cells typically exist in chronically hypoxic conditions in vivo. Therefore, cancer cells develop complex interactions that affect several pathways.

The most important finding in this study was the reciprocal relationship between SCGB2A1 expression and treatment resistance. We hypothesized that treatment resistance was caused by the development of cancer stemness, because our data showed that the expression of SCGB2Al was correlated with the expression of Wnt, Zebl and Twist. The sphere formation assay is commonly used to detect CSCs in vitro. As we expected, SCGB2A1-expressing cells showed more abundant sphere formation than control cells. This cancer-stemness property may partly explain why SCGB2A1 expression was associated with chemoresistance and radioresistance in CRC. These findings suggested that SCGB2A1-expressing cells have enhanced malignancy potential. Our data also suggested that SCGB2A1 may represent a novel therapeutic target.

In conclusion, we showed that SCGB2A1 represents a novel prognostic factor for CRC. SCGB2A1 correlated with chemoresistance, radioresistance, and cancer cell stemness.

\section{Acknowledgements}

This study was supported by a Grant-in-Aid for Cancer Research from the Ministry of Education, Science, Sports and Culture Technology, Japan (grant 21390360).

\section{References}

1. Jemal A, Siegel R, Xu J and Ward E: Cancer statistics, 2010. CA Cancer J Clin 60: 277-300, 2010

2. Vaupel P, Briest $S$ and Hockel M: Hypoxia in breast cancer: pathogenesis, characterization and biological/therapeutic implications. Wien Med Wochenschr 152: 334-342, 2002.
3. Sooriakumaran P and Kaba R: Angiogenesis and the tumour hypoxia response in prostate cancer: a review. Int J Surg 3: 61-67, 2005.

4. Higgins LH, Withers HG, Garbens A, et al: Hypoxia and the metabolic phenotype of prostate cancer cells. Biochim Biophys Acta 1787: 1433-1443, 2009.

5. Jensen RL: Brain tumor hypoxia: tumorigenesis, angiogenesis, imaging, pseudoprogression, and as a therapeutic target. J Neurooncol 92: 317-335, 2009.

6. O'Connell MP, Marchbank K, Webster MR, et al: Hypoxia induces phenotypic plasticity and therapy resistance in melanoma via the tyrosine kinase receptors ROR1 and ROR2. Cancer Discov: Oct 8, 2013 (Epub ahead of print). doi: 10.1158/21598290.CD-13-0005 2013

7. Zeng W, Yang D, Long T, et al: CD147 promotes melanoma progression through hypoxia-induced MMP2 activation. Curr Mol Med: Oct 3, 2013 (Epub ahead of print).

8. Lee GW, Go SI, Cho YJ, et al: Hypoxia-inducible factor-1alpha and excision repair cross-complementing 1 in patients with small cell lung cancer who received front-line platinum-based chemotherapy: a retrospective study. J Thorac Oncol 7: 528-534, 2012.

9. Zhang L, Huang G, Li X, et al: Hypoxia induces epithelial-mesenchymal transition via activation of SNAI1 by hypoxia-inducible factor -1alpha in hepatocellular carcinoma. BMC Cancer 13: 108, 2013.

10. Liu Y, Zhang JB, Qin Y, et al: PROX1 promotes hepatocellular carcinoma metastasis by way of up-regulating hypoxia-inducible factor 1alpha expression and protein stability. Hepatology 58: 692-705, 2013.

11. Selvendiran K, Bratasz A, Kuppusamy ML, Tazi MF, Rivera BK and Kuppusamy P: Hypoxia induces chemoresistance in ovarian cancer cells by activation of signal transducer and activator of transcription 3. Int J Cancer 125: 2198-2204, 2009.

12. Liang D, Ma Y, Liu J, et al: The hypoxic microenvironment upgrades stem-like properties of ovarian cancer cells. BMC Cancer 12: 201, 2012.

13. Chang LH, Chen CH, Huang DY, Pai HC, Pan SL and Teng CM: Thrombin induces expression of twist and cell motility via the hypoxia-inducible factor-1alpha translational pathway in colorectal cancer cells. J Cell Physiol 226: 1060-1068, 2011.

14. Semenza GL: Hypoxia and cancer. Cancer Metastasis Rev 26: 223-224, 2007.

15. Harris AL: Hypoxia - a key regulatory factor in tumour growth. Nat Rev Cancer 2: 38-47, 2002.

16. Kizaka-Kondoh S, Inoue M, Harada $\mathrm{H}$ and Hiraoka M: Tumor hypoxia: a target for selective cancer therapy. Cancer Sci 94: 1021-1028, 2003.

17. Semenza GL: Targeting HIF-1 for cancer therapy. Nat Rev Cancer 3: 721-732, 2003.

18. Hurwitz H, Fehrenbacher L, Novotny W, et al: Bevacizumab plus irinotecan, fluorouracil, and leucovorin for metastatic colorectal cancer. N Engl J Med 350: 2335-2342, 2004.

19. Uemura M, Yamamoto H, Takemasa I, et al: Jumonji domain containing $1 \mathrm{~A}$ is a novel prognostic marker for colorectal cancer: in vivo identification from hypoxic tumor cells. Clin Cancer Res 16: 4636-4646, 2010.

20. Uemura M, Yamamoto H, Takemasa I, et al: Hypoxia-inducible adrenomedullin in colorectal cancer. Anticancer Res 31: 507-514, 2011.

21. Yamamoto H, Tei M, Uemura M, et al: Ephrin-A1 mRNA is associated with poor prognosis of colorectal cancer. Int J Oncol 42: 549-555, 2012.

22. Noda T, Yamamoto H, Takemasa I, et al: PLOD2 induced under hypoxia is a novel prognostic factor for hepatocellular carcinoma after curative resection. Liver Int 32: 110-118, 2012.

23. Aihara T, Fujiwara Y, Ooka M, Sakita I, Tamaki Y and Monden M: Mammaglobin B as a novel marker for detection of breast cancer micrometastases in axillary lymph nodes by reverse transcription-polymerase chain reaction. Breast Cancer Res Treat 58: 137-140, 1999.

24. Okami J, Dohno K, Sakon M, et al: Genetic detection for micrometastasis in lymph node of biliary tract carcinoma. Clin Cancer Res 6: 2326-2332, 2000.

25. Aihara T, Fujiwara Y, Miyake Y, et al: Mammaglobin B gene as a novel marker for lymph node micrometastasis in patients with abdominal cancers. Cancer Lett 150: 79-84, 2000.

26. Ouellette RJ, Richard D and Maicas E: RT-PCR for mammaglobin genes, MGB1 and MGB2, identifies breast cancer micrometastases in sentinel lymph nodes. Am J Clin Pathol 121: 637-643, 2004. 
27. Tassi RA, Bignotti E, Falchetti M, et al: Mammaglobin B expression in human endometrial cancer. Int J Gynecol Cancer 18: 1090-1096, 2008.

28. Tassi RA, Calza S, Ravaggi A, et al: Mammaglobin B is an independent prognostic marker in epithelial ovarian cancer and its expression is associated with reduced risk of disease recurrence. BMC Cancer 9: 253, 2009.

29. Bellone S, Tassi R, Betti M, et al: Mammaglobin B (SCGB2A1) is a novel tumour antigen highly differentially expressed in al major histological types of ovarian cancer: implications for ovarian cancer immunotherapy. Br J Cancer 109: 462-471, 2013.

30. Mohrin M, Bourke E, Alexander D, et al: Hematopoietic stem cell quiescence promotes error-prone DNA repair and mutagenesis. Cell Stem Cell 7: 174-185, 2010.

31. Adikrisna R, Tanaka S, Muramatsu S, et al: Identification of pancreatic cancer stem cells and selective toxicity of chemotherapeutic agents. Gastroenterology 143: 234-245, 2012.

32. Miyake M, Takemasa I, Matoba R, et al: Heterogeneity of colorectal cancers and extraction of discriminator gene signatures for personalized prediction of prognosis. Int J Oncol 39: 781-789, 2011.

33. Takeno A, Takemasa I, Doki Y, et al: Integrative approach for differentially overexpressed genes in gastric cancer by combining large-scale gene expression profiling and network analysis. Br J Cancer 99: 1307-1315, 2008.

34. Takaishi S, Okumura T, Tu S, et al: Identification of gastric cancer stem cells using the cell surface marker CD44. Stem Cells 27: 1006-1020, 2009.
35. Vermeulen L, De Sousa EMF, van der Heijden M, et al: Wnt activity defines colon cancer stem cells and is regulated by the microenvironment. Nat Cell Biol 12: 468-476, 2010.

36. Singh A and Settleman J: EMT, cancer stem cells and drug resistance: an emerging axis of evil in the war on cancer. Oncogene 29: 4741-4751, 2010.

37. Ni J, Kalff-Suske M, Gentz R, Schageman J, Beato M and Klug J: All human genes of the uteroglobin family are localized on chromosome 11q12.2 and form a dense cluster. Ann NY Acad Sci 923: 25-42, 2000.

38. Becker RM, Darrow C, Zimonjic DB, Popescu NC, Watson MA and Fleming TP: Identification of mammaglobin B, a novel member of the uteroglobin gene family. Genomics 54: 70-78, 1998.

39. Fiegl M, Haun M, Massoner A, et al: Combination of cytology, fluorescence in situ hybridization for aneuploidy, and reverse-transcriptase polymerase chain reaction for human mammaglobin/mammaglobin B expression improves diagnosis of malignant effusions. J Clin Oncol 22: 474-483, 2004.

40. Brennan DJ, Jirstrom K, Kronblad A, et al: CA IX is an independent prognostic marker in premenopausal breast cancer patients with one to three positive lymph nodes and a putative marker of radiation resistance. Clin Cancer Res 12: 6421-6431, 2006. 